\title{
Analysis of therapeutic effect of intermittent and continuous phototherapy on neonatal hemolytic jaundice
}

\author{
SHIYING ZHOU ${ }^{1}$, XIAOYAN WU ${ }^{2}$, AIHUA MA ${ }^{3}$, MIN ZHANG $^{4}$ and YANLI LIU ${ }^{1}$ \\ ${ }^{1}$ Department of Pediatric Internal Medicine, Qilu Hospital of Shandong University (Qingdao), Qingdao, \\ Shandong 266000; ${ }^{2}$ Department of Pediatrics, People's Hospital of Chiping, Liaocheng, Shandong 252000; \\ ${ }^{3}$ PIVAS; ${ }^{4}$ Department of Stomatology, The People's Hospital of Zhangqiu Area, Jinan, Shandong 250200, P.R. China
}

Received November 15, 2018; Accepted March 14, 2019

DOI: $10.3892 / \mathrm{etm} .2019 .7432$

\begin{abstract}
Clinical efficacy and adverse reaction rates of $\mathrm{ABO}$ hemolytic jaundice in patients with continuous and intermittent blue light irradiation were compared, to provide reference for clinical treatment of neonatal ABO hemolytic jaundice. A retrospective analysis of 307 patients with neonatal hemolytic jaundice admitted to Qilu Hospital of Shandong University (Qingdao) from January 2010 to December 2017 was undertaken. A total of 165 cases of children with continuous blue light irradiation and 142 cases of intermittent blue light irradiation were analyzed. Also the serum bilirubin levels, phototherapy time and frequency, treatment efficiency and adverse reaction rates were compared between the groups. The phototherapy time of children in the continuous phototherapy group was significantly higher from the intermittent phototherapy group, and the difference was statistically significant $(\mathrm{t}=26.800$, $\mathrm{P}<0.001)$. Before treatment, there was no significant difference in serum bilirubin levels between continuous and intermittent phototherapy groups $(\mathrm{P}>0.050)$. Serum bilirubin levels of patients in continuous and intermittent phototherapy groups were lower than both previous and before treatment period, and differences were statistically significant $(\mathrm{P}<0.001)$. The overall effective rate of the continuous phototherapy group was higher than that of the intermittent phototherapy group $(\mathrm{P}>0.050)$. The adverse reaction rates after treatment in the continuous phototherapy group was significantly higher than the intermittent phototherapy group $(\mathrm{P}<0.050)$. After the symptomatic treatment in children, the adverse reactions ceased. The therapeutic effect of intermittent blue light irradiation on neonatal ABO hemolytic jaundice was consistent with the continuous blue light irradiation treatment, and the
\end{abstract}

Correspondence to: Dr Yanli Liu, Department of Pediatric Internal Medicine, Qilu Hospital of Shandong University (Qingdao), 758 Hefei Road, Qingdao, Shandong 266000, P.R. China E-mail: evn8u9@163.com

Key words: continuous blue light irradiation, intermittent blue light irradiation, neonatal ABO hemolytic jaundice, clinical efficacy, adverse reaction rates intermittent blue light irradiation treatment has a low adverse reaction rate, and is worth promotion in clinical practice.

\section{Introduction}

Neonatal jaundice is a common disease in neonatology. Due to the immature liver function in neonates leading to abnormal bilirubin metabolism and causing an abnormal increase in bilirubin levels of blood, also called neonatal hyperbilirubinemia. According to etiology, it can be divided into physiological jaundice and pathological jaundice $(1,2)$. Neonatal jaundice occurs mostly in premature infants, and the main clinical manifestations are yellow stains on the sclera, skin and mucosa membranes of infants. However, the symptoms are painless, so it is unnoticeable for parents (3-5). Currently, the incidence of neonatal pathological jaundice is still high, and the incidence rates of jaundice in $\mathrm{ABO}$ hemolytic neonates is extremely high (6). Neonatal ABO is a neonatal homologous immune hemolytic disease, due to the incompatibility of maternal and infant $\mathrm{ABO}$ blood type, an extremely fast hemolysis rate during the process of hemolysis in children will lead to a direct rise in blood bilirubin levels, and will gradually develop into pathological ABO hemolytic jaundice $(7,8)$. ABO hemolytic jaundice has an extremely severe effect, which can cause neonatal bilirubin encephalopathy if treatment is not given in an appropriate time, and further causes damage to the neonatal nervous system, intelligence and/or hearing loss. In severe cases, it can threaten the life of a newborn $(3,9)$. Therefore, early and active treatment is very important for neonatal ABO hemolytic jaundice, and it is also a topic that is currently highly valued in medical studies.

Currently, phototherapy treatment is a widely used method for treating neonatal jaundice. It is easy to use, has a low cost and good effect, so it is accepted by most of the medical staff (10). It 's easier for serum bilirubin molecules to absorb blue light than green and ultraviolet light. Therefore, blue light irradiation has become the preferred treatment. Also it rapidly reduces the serum bilirubin content in children by converting indirect bilirubin into a non-toxic water-soluble derivative light-bilirubin isomer $(11,12)$. Continuous irradiation is mostly used clinically, however, there are documents showing that a long irradiation time can cause many adverse reactions (13). According to the research by Maisels (14), reducing the 
duration of phototherapy can decrease the adverse reactions caused by phototherapy and helps the nurse care and treatment of children. Therefore, this study retrospectively analyzed neonatal ABO hemolytic jaundice in Qilu Hospital of Shandong University (Qingdao, China) for continuous and intermittent blue light irradiation. Serum bilirubin levels were measured before and after treatment in children, and all the indicators between the groups were recorded and compared. This study provides a reference for the clinical treatment of neonatal $\mathrm{ABO}$ hemolytic jaundice.

\section{Patients and methods}

Patient information. Retrospective analysis of 307 patients with neonatal ABO hemolytic jaundice admitted to Qilu Hospital of Shandong University (Qingdao) from January 2010 to December 2017 was performed. A total of 165 children treated with continuous blue light irradiation were the continuous phototherapy group, including 89 males, and 76 females, average age $5.87 \pm 0.65$ days, average weight $3.92 \pm 0.27 \mathrm{~kg}$ and mean disease duration $5.22 \pm 0.86$ days. A total of 142 children treated with intermittent blue light irradiation were the intermittent phototherapy group, with 74 males, and 68 females, average age $5.79 \pm 0.84$ days, average weight $3.88 \pm 0.38 \mathrm{~kg}$ and mean disease duration $5.17 \pm 0.62$ days.

Inclusion criteria: i) Children diagnosed with neonatal ABO hemolytic jaundice; ii) age <1 week, disease duration 1-7 days; iii) total serum bilirubin levels of children $>220.60 \mu \mathrm{mol} / \mathrm{l}$; iv) with complete cases; and v) never received treatments from other hospitals. Exclusion criteria: i) Children with contraindications for treatment with blue light irradiation; ii) parents who refused to treat children with blue light radiation; and iii) children with serious infections and diseases.

This study was approved by the Ethics Committee of Qilu Hospital of Shandong University (Qingdao). Patients who participated in this research had complete clinical data. Signed informed consents were obtained from the parents of the child patients.

Methods. Children in the continuous and the intermittent phototherapy group received prompt correction of the acid-base imbalance, anti-infection treatment, nutritional support, and heat preservation. Both groups of children were treated with blue double-sided light irradiation (YLG-1 type; Shanghai Medical Thermostat Equipment Factory, Shanghai, China) on the basis of conventional treatment. The perineum of children was protected by black cotton diapers, and the eyes were protected by a black eye mask, and children were appropriately constrained. The temperature was set to $30-32^{\circ} \mathrm{C}$ and the humidity was set to 55-65\%. In order to ensure that the skin of children receives light evenly, the light distance was adjusted to $25 \mathrm{~cm}$, and the blue light wavelength was set as $425-475 \mathrm{~nm}$ and the power to $160 \mathrm{~W}$. Children in the phototherapy group were treated with continuous $12-18 \mathrm{~h}$ of blue light irradiation with a stop of 8-12 $\mathrm{h}$ in between. Children in the intermittent phototherapy group were treated with intermittent blue light: $3-5 \mathrm{~h}$ of blue light of irradiation and a stop of 2-4 h in between. The course of treatment for each group was $72 \mathrm{~h}$. During the treatment, yellow staining on the skin and sclera as well as all the vital signs were closely monitored. The bilirubin level of children was measured by bilirubin measuring instrument (Beckman automatic biochemical analyzer) before and after 24, 48 and $72 \mathrm{~h}$ of treatment. The bilirubin levels, time of phototherapy, phototherapy frequency, treatment efficiency and adverse reaction rates were recorded and compared between the groups.

Total efficiency evaluation criteria in clinic. Efficacy judgment criteria: i) Fully healed: The yellow stains on the skin, sclera and entire body of children completely disappeared; ii) the serum bilirubin level of children was at a normal content of 3-25 $\mu \mathrm{mol} / \mathrm{l}$; iii) effective: after the treatment, the yellow stains on the skin, sclera and entire body of children has partially gone and the serum bilirubin level of children has decreased significantly, however, it still did not return to the normal value; and iv) ineffective: after the treatment, the yellow stains on the skin, sclera and entire body of the children did not disappear at all and the serum bilirubin level of children did not decrease. Clinical total effective rate $=$ (effective number of cases + number of effective cases) / total number of cases $\times 100 \%$.

Statistical analysis. Statistical analysis was carried out using the software system of SPSS 17.1 (SPSS, Inc., Chicago, IL, USA). The data counting was expressed as a percentage [n (\%)]. The difference between the groups was compared by Chi-square test. Measurement of data were expressed as mean \pm standard deviation, the difference between the groups was compared by t-test. Comparison of multiple time points used repeated measures of analysis of variance with Least Significant Difference test. $\mathrm{P}<0.05$ was considered to indicate a statistically significant difference.

\section{Results}

Comparison of patients' clinical data. In order to make the experimental results accurate and credible, sex, age, weight, duration of disease and delivery period between groups were compared. The difference was not statistically significant ( $P>0.05)$. It shows that there is comparability between the groups of patients (Table I).

Comparison of phototherapy time and frequency in children between continuous and intermittent phototherapy groups. Phototherapy time of children in continuous phototherapy group was significantly higher than the intermittent phototherapy group, and the difference was statistically significant $(\mathrm{t}=26.800$, $\mathrm{P}<0.001)$. There was no significant difference in the number of phototherapy between phototherapy and intermittent phototherapy groups ( $\mathrm{P}>0.050$; Table II).

Comparison of serum bilirubin levels in children between continuous and intermittent phototherapy groups before and after 24, 48 and $72 \mathrm{~h}$ of treatment. Before treatment, there was no significant difference in serum bilirubin levels between continuous and intermittent phototherapy groups $(\mathrm{P}>0.050)$. There was no significant difference in serum bilirubin levels between continuous and intermittent phototherapy groups at 24, 48 and $72 \mathrm{~h}$ after treatment $(\mathrm{P}>0.050)$. The serum bilirubin levels of patients in the continuous and the intermittent 
Table I. Basic information of patients between the continuous and the intermittent phototherapy groups [n (\%)].

\begin{tabular}{|c|c|c|c|c|}
\hline Variables & $\begin{array}{l}\text { Continuous } \\
\text { phototherapy group } \\
(\mathrm{n}=165)\end{array}$ & $\begin{array}{c}\text { Intermittent } \\
\text { phototherapy group } \\
(\mathrm{n}=142)\end{array}$ & $\begin{array}{c}\text { t/Chi-square } \\
\text { test }\end{array}$ & P-value \\
\hline Sex & & & 0.102 & 0.749 \\
\hline Male & $89(53.94)$ & $74(52.11)$ & & \\
\hline Female & $76(46.06)$ & $68(47.89)$ & & \\
\hline Age (days) & $5.87 \pm 0.65$ & $5.79 \pm 0.84$ & 0.940 & 0.348 \\
\hline Weight (kg) & $3.92 \pm 0.27$ & $3.88 \pm 0.38$ & 1.074 & 0.284 \\
\hline Disease duration (days) & $5.22 \pm 0.86$ & $5.17 \pm 0.62$ & 0.576 & 0.565 \\
\hline With or without deformity & & & 0.204 & 0.652 \\
\hline With deformity & $2(1.12)$ & $1(0.70)$ & & \\
\hline Without deformity & $163(98.79)$ & $141(99.30)$ & & \\
\hline Maternity period & & & 1.202 & 0.548 \\
\hline Premature & $115(69.70)$ & $91(64.08)$ & & \\
\hline Full-term & $43(26.06)$ & $45(31.69)$ & & \\
\hline Exceeded & $7(4.24)$ & $6(4.23)$ & & \\
\hline
\end{tabular}

Table II. Comparison of phototherapy time and frequency in children between the phototherapy and the intermittent phototherapy groups (mean \pm standard deviation).

\begin{tabular}{lcrr}
\hline & $\begin{array}{c}\text { Continuous } \\
\text { phototherapy group } \\
(\mathrm{n}=165)\end{array}$ & $\begin{array}{c}\text { Intermittent } \\
\text { phototherapy group } \\
(\mathrm{n}=142)\end{array}$ & $\mathrm{t}$ \\
Items & $29.54 \pm 3.28$ & $20.18 \pm 2.76$ & 26.800 \\
Time of phototherapy (h) & $2.61 \pm 0.18$ & $2.65 \pm 0.24$ & $<0.001$ \\
Number of phototherapy (times) & $\begin{array}{r}\text { P-value } \\
0.097\end{array}$ \\
\hline
\end{tabular}

Table III. Comparison of serum bilirubin $(\mu \mathrm{mol} / \mathrm{l})$ levels in children between the continuous and the intermittent phototherapy groups before and after 24,48 and $72 \mathrm{~h}$ of treatment.

\begin{tabular}{lccc}
\hline & $\begin{array}{c}\text { Continuous } \\
\text { phototherapy group } \\
(\mathrm{n}=165)\end{array}$ & $\begin{array}{c}\text { The intermittent } \\
\text { phototherapy group } \\
(\mathrm{n}=142)\end{array}$ & $\mathrm{t}$ \\
Items & $284.25 \pm 3.68$ & $283.67 \pm 3.59$ & 1.392 \\
Before treatment & $211.54 \pm 2.50^{\mathrm{a}}$ & $212.02 \pm 2.34^{\mathrm{a}}$ & 1.728 \\
24 h after treatment & $139.49 \pm 3.28^{\mathrm{a}}$ & $140.23 \pm 3.75^{\mathrm{a}}$ & 1.844 \\
48 h after treatment & $49.98 \pm 2.64^{\mathrm{a}}$ & $50.54 \pm 2.66^{\mathrm{a}}$ & 1.847 \\
72 h after treatment & 176534.000 & 142991.000 & 0.085 \\
F & $<0.001$ & $<0.001$ & 0.066 \\
P-value & & & \\
\hline
\end{tabular}

${ }^{a}$ The difference was statistically different $(\mathrm{P}<0.050)$ compared with the previous time point.

phototherapy groups were lower than both previous period and before treatment $(\mathrm{P}<0.001$; Table III and Fig. 1).

Comparison of overall efficiency in children between continuous and intermittent phototherapy groups after treatment. The number of partially-effective, significantly-effective and ineffective in continuous phototherapy group was 41, 107 and 17, respectively. The number of partially-effective, significantly-effective and ineffective in the intermittent phototherapy group was 38,88 and 16, respectively. The overall effective rate was $89.70 \%$ in the continuous phototherapy group and $88.73 \%$ in the intermittent phototherapy group. There was no significant difference between the groups ( $\mathrm{P}>0.050$; Table IV). 
Table IV. Comparison of overall efficiency in children between the continuous and the intermittent phototherapy groups after treatment.

\begin{tabular}{lcccc}
\hline Items & $\begin{array}{c}\text { Partially- } \\
\text { effective }\end{array}$ & $\begin{array}{c}\text { Significantly- } \\
\text { effective }\end{array}$ & Ineffective & $\begin{array}{c}\text { Overall } \\
\text { efficiency }\end{array}$ \\
\hline Continuous phototherapy group $(\mathrm{n}=165)$ & 41 & 107 & 17 & $148(89.70)$ \\
Intermittent phototherapy group $(\mathrm{n}=142)$ & 38 & 88 & 16 & $126(88.73)$ \\
Chi-square test & - & - & - & 0.074 \\
P-value & - & - & - & 0.786 \\
\hline
\end{tabular}

Table V. Comparison of adverse reactions of children between the continuous and the intermittent phototherapy groups after treatment $[\mathrm{n}(\%)]$.

\begin{tabular}{lcccc}
\hline Groups & $\begin{array}{c}\text { Continuous } \\
\text { phototherapy group } \\
(\mathrm{n}=165)\end{array}$ & $\begin{array}{c}\text { Intermittent } \\
\text { phototherapy group } \\
(\mathrm{n}=142)\end{array}$ & $\begin{array}{c}\text { Chi-square } \\
\text { test }\end{array}$ & P-value \\
\hline Fever & $27(16.36)$ & $11(7.75)$ & - & - \\
Skin rash & $22(13.33)$ & $13(9.15)$ & - & - \\
Diarrhea & $12(7.27)$ & $7(4.93)$ & - & - \\
Others & $7(4.24)$ & $4(2.82)$ & - & - \\
Adverse reaction rates & $68(41.21)$ & $35(24.65)$ & 9.393 & 0.002 \\
\hline
\end{tabular}

Comparison of adverse reaction rates in children between continuous and intermittent phototherapy groups after treatment. The adverse reaction rates of patients in continuous phototherapy group was $41.21 \%$, which was significantly higher than intermittent phototherapy group (24.65\%). The difference was statistically significant $(\mathrm{P}<0.050)$. Adverse reactions of children ceased after the symptomatic treatment (Table V).

\section{Discussion}

Approximately $60 \%$ of full-term infants and $80 \%$ of premature infants develop jaundice due to hyperbilirubinemia during neonatal period. Also 5-10\% of them require treatment by phototherapy (15), and $60 \%$ of newborns have clinical jaundice symptoms in the first week after birth. Also ABO-incompatibility is the most common cause of hemolytic disease in newborns, occuring commonly in maternal type $\mathrm{O}$ blood and type $\mathrm{A}$ or $\mathrm{B}$ blood in newborns as well as in the $\mathrm{ABO}$ hemolytic jaundice $(16,17)$. ABO hemolytic jaundice is a serious pathological jaundice, which can cause neonatal growth and development disorders and irreversible effects on the nervous system if patients receive inappropriate or not well-timed treatment (18). Some documents have shown that phototherapy irradiation can make bilirubin from the serum of children absorb certain wavelength of light, resulting in the transformation of its structure and properties. Excreting from the body through the biliary tract or urethra and reducing the serum bilirubin levels in children. However, there are also documents showing that the phototherapy exposure can cause related complications $(19,20)$.

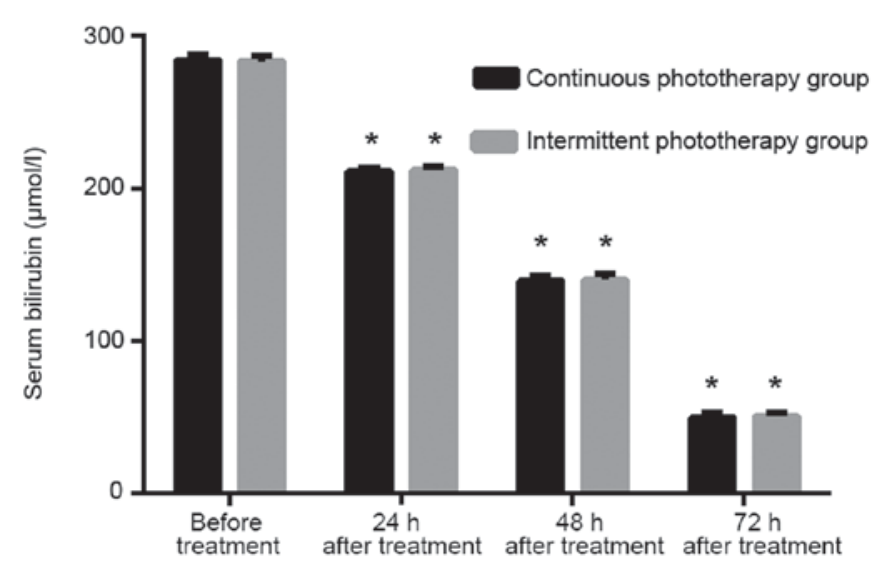

Figure 1. Comparison of serum bilirubin levels of children between the continuous and the intermittent phototherapy groups at 24, 48 and $72 \mathrm{~h}$ before and after treatment. Before treatment, there was no significant difference in serum bilirubin levels between the continuous and the intermittent phototherapy groups $(\mathrm{P}>0.050)$. There was no significant difference in serum bilirubin levels between the continuous and the intermittent phototherapy groups at 24,48 and $72 \mathrm{~h}$ after treatment $(\mathrm{P}>0.050)$. The serum bilirubin levels of patients in the continuous and the intermittent phototherapy groups were lower than the previous period and before treatment, and the differences were statistically significant $(\mathrm{P}<0.001)$. Difference is statistically different compared with the previous time point $\left({ }^{*} \mathrm{P}<0.050\right)$.

Our study reviewed 307 patients with neonatal hemolytic jaundice admitted to Qilu Hospital of Shandong University (Qingdao) from January 2010 to December 2017. A total 165 patients with continuous blue light irradiation and 142 patients with intermittent blue light irradiation were analyzed. Also the serum bilirubin levels, phototherapy time and frequency, treatment efficiency and adverse reactions 
were compared between the groups. The phototherapy time of children in the continuous phototherapy group was significantly higher than the intermittent phototherapy group, and the difference was statistically significant. Based on the comparison of phototherapy time, we compared the serum bilirubin levels and the efficacy of patients between the continuous and the intermittent phototherapy groups before and after treatment. Our results showed that there was no statistically significant difference in serum bilirubin levels between the continuous and the intermittent phototherapy groups at 24,48 and $72 \mathrm{~h}$ before and after treatment. The serum bilirubin levels of patients between the continuous and the intermittent phototherapy groups were lower than the previous period and before treatment, and the differences were statistically significant. The overall effective rate in the continuous phototherapy group was $89.70 \%$, and the overall effective rate in the intermittent phototherapy group was $88.73 \%$. The difference between the groups was not statistically significant. According to Sachdeva et al (21) in the neonatal intensive care unit of jaundice neonatal irradiation treatment study, it was found that the clinical efficacy between intermittent single-light irradiation in the treatment of neonatal hyperbilirubinemia and continuous single-light irradiation were consistent. However, Lamola et al (22) found that there was no significant difference in serum bilirubin levels between the intermittent and continuous phototherapy at 12, 24, 36 and $48 \mathrm{~h}$ after treatment $(\mathrm{P}>0.05)$, which further proved our research results. Moreover, in the case of small difference in efficacy, intermittent phototherapy can save medical costs and reduce the anxiety of family members (22). In the later stage, we found that the adverse reaction rates in the continuous phototherapy group was $41.21 \%$ after treatment, which was significantly higher than the intermittent phototherapy group (24.65\%). The difference was statistically significant. Furthermore, there are documents showing that the continuous phototherapy exposure can cause skin rash in children (23). According to Hansen (24), phototherapy may be harmful and the time of phototherapy is the factor for determination. Therefore, we can speculate that long exposure time of phototherapy can lead to increased adverse reactions in children. Currently, there is no relevant data on the adverse reaction rates in the continuous or intermittent blue light irradiation. However, there is increasing evidence showing that long-term exposure of phototherapy for the treatment of jaundice can be harmful to children, and should be used as minimally as possible with the same efficacy $(25,26)$.

In this experiment, due to the small number of $\mathrm{ABO}$ hemolytic jaundice patients in Qilu Hospital of Shandong University (Qingdao), the selected subjects are limited and there may have certain contingency within our results. Also due to the large bases of our neonatal research variables, a longer follow-up investigation on these subjects will be conducted.

In summary, the treatment effect of the intermittent blue light irradiation on neonatal ABO hemolytic jaundice is consistent with the continuous blue light irradiation treatment. Also the intermittent blue irradiation has a low adverse reaction rate, so it is worthy of promotion in clinical practice.

\section{Acknowledgements}

Not applicable.

\section{Funding}

No funding was received.

\section{Availability of data and materials}

The datasets used and/or analyzed during the present study are available from the corresponding author on reasonable request.

\section{Authors' contributions}

SZ wrote the manuscript. SZ and YZ and MZ conceived and designed the study and worked on total efficiency evaluation. XW and AM collected the patient data. MZ and YL analyzed and interpreted the patient data regarding the neonatal hemolytic. All authors read and approved the final manuscript.

\section{Ethics approval and consent to participate}

The study was approved by The Ethics Committee of Qilu Hospital of Shandong University (Qingdao, China). Patients who participated in this research had complete clinical data. Signed informed consents were obtained from the parents of the child patients.

\section{Patient consent for publication}

Not applicable.

\section{Competing interests}

The authors declare that they have no competing interests.

\section{References}

1. Chang PF, Lin YC, Liu K, Yeh SJ and Ni YH: Identifying term breast-fed infants at risk of significant hyperbilirubinemia. Pediatr Res 74: 408-412, 2013.

2. Moncrieff G: Bilirubin in the newborn: Physiology and pathophysiology. Br J Midwifery 26: 362-370, 2018.

3. Christensen RD, Nussenzveig RH, Yaish HM, Henry E, Eggert LD and Agarwal AM: Causes of hemolysis in neonates with extreme hyperbilirubinemia. J Perinatol 34: 616-619, 2014.

4. Bjerre JV, Petersen JR and Ebbesen F: Surveillance of extreme hyperbilirubinaemia in Denmark. A method to identify the newborn infants. Acta Paediatr 97: 1030-1034, 2008.

5. Olusanya BO, Teeple S and Kassebaum NJ: The contribution of neonatal jaundice to global child mortality: findings from the GBD 2016 study. Pediatrics 141: e20171471, 2018.

6. Lee BK, Le Ray I, Sun JY, Wikman A, Reilly M and Johansson S: Haemolytic and nonhaemolytic neonatal jaundice have different risk factor profiles. Acta Paediatr 105: 1444-1450, 2016.

7. Christensen RD and Yaish HM: Hemolytic disorders causing severe neonatal hyperbilirubinemia. Clin Perinatol 42: 515-527, 2015.

8. Agarwal V, Singh V, Goel SP and Gupta B: Maternal and neonatal factors affecting physiological jaundice in western U.P. Indian J Physiol Pharmacol 51: 203-206, 2007.

9. Wei CC, Chang CH, Lin CL, Chang SN, Li TC and $\mathrm{Kao} \mathrm{CH}$ : Neonatal jaundice and increased risk of attention-deficit hyperactivity disorder: A population-based cohort study. J Child Psychol Psychiatry 56: 460-467, 2015.

10. Maisels MJ and McDonagh AF: Phototherapy for neonatal jaundice. N Engl J Med 358: 920-928, 2008.

11. Itoh S, Okada H, Kuboi $\mathrm{T}$ and Kusaka T: Phototherapy for neonatal hyperbilirubinemia. Pediatr Int (Roma) 59: 959-966, 2017. 
12. Ebbesen F, Madsen PH, Vandborg PK, Jakobsen LH, Trydal T and Vreman HJ: Bilirubin isomer distribution in jaundiced neonates during phototherapy with LED light centered at $497 \mathrm{~nm}$ (turquoise) vs. $459 \mathrm{~nm}$ (blue). Pediatr Res 80: 511-515, 2016.

13. Mreihil K, Benth JS, Stensvold HJ, Nakstad B and Hansen TWR; Norwegian NICU Phototherapy Study Group; Norwegian neonatal network: Phototherapy is commonly used for neonatal jaundice but greater control is needed to avoid toxicity in the most vulnerable infants. Acta Paediatr 107: 611-619, 2018.

14. Maisels MJ: Phototherapy in the neonatal intensive care unit-quantity and quality. Acta Paediatr 107: 551-553, 2018.

15. Bhutani VK and Wong R: Bilirubin-induced neurologic dysfunction (BIND). Semin Fetal Neonatal Med 20: 1, 2015

16. Zecca E, Barone G, De Luca D, Marra R, Tiberi E and Romagnoli C: Skin bilirubin measurement during phototherapy in preterm and term newborn infants. Early Hum Dev 85: 537-540, 2009

17. Kaplan M, Hammerman C, Renbaum P, Klein G and Levy-Lahad E: Gilbert's syndrome and hyperbilirubinaemia in ABO-incompatible neonates. Lancet 356: 652-653, 2000.

18. Jiao Y, Jin Y, Meng $\mathrm{H}$ and Wen M: An analysis on treatment effect of blue light phototherapy combined with Bifico in treating neonatal hemolytic jaundice. Exp Ther Med 16: 1360-1364, 2018

19. Mreihil K, Madsen P, Nakstad B, Benth JS, Ebbesen F and Hansen TW: Early formation of bilirubin isomers during phototherapy for neonatal jaundice: effects of single vs. double fluorescent lamps vs. photodiodes. Pediatr Res 78: 56-62, 2015.
20. Oláh J, Tóth-Molnár E, Kemény L and Csoma Z: Long-term hazards of neonatal blue-light phototherapy. Br J Dermatol 169: 243-249, 2013.

21. Sachdeva M, Murki S, Oleti TP and Kandraju H: Intermittent versus continuous phototherapy for the treatment of neonatal non-hemolytic moderate hyperbilirubinemia in infants more than 34 weeks of gestational age: a randomized controlled trial. Eur J Pediatr 174: 177-181, 2015.

22. Lamola AA, Bhutani VK, Wong RJ, Stevenson DK and McDonagh AF: The effect of hematocrit on the efficacy of phototherapy for neonatal jaundice. Pediatr Res 74: 54-60, 2013.

23. Maisels MJ, Ramaswamy D and Kring EA: Does phototherapy cause benign skin rashes in newborn infants? Acta Paediatr 103: e133-e135, 2014.

24. Hansen TW: Let there be light - but should there be less? J Perinatol 32: 649-651, 2012.

25. Mills JF and Tudehope D: Fibreoptic phototherapy for neonatal jaundice. Cochrane Database Syst Rev 1: CD002060, 2001.

26. Stokowski LA: Fundamentals of phototherapy for neonatal jaundice. Adv Neonatal Care 11 (Suppl 5): S10-S21, 2011.

This work is licensed under a Creative Commons Attribution-NonCommercial-NoDerivatives 4.0 International (CC BY-NC-ND 4.0) License. 